\title{
Enzyme-DNA Biocolloids for DNA Adduct and Reactive Metabolite Detection by Chromatography-Mass Spectrometry
}

Besnik Bajrami, Eli G. Hvastkovs, Gary Jensen, John B. Schenkman, and James F. Rusling

\section{SUPPORTING INFORMATION}

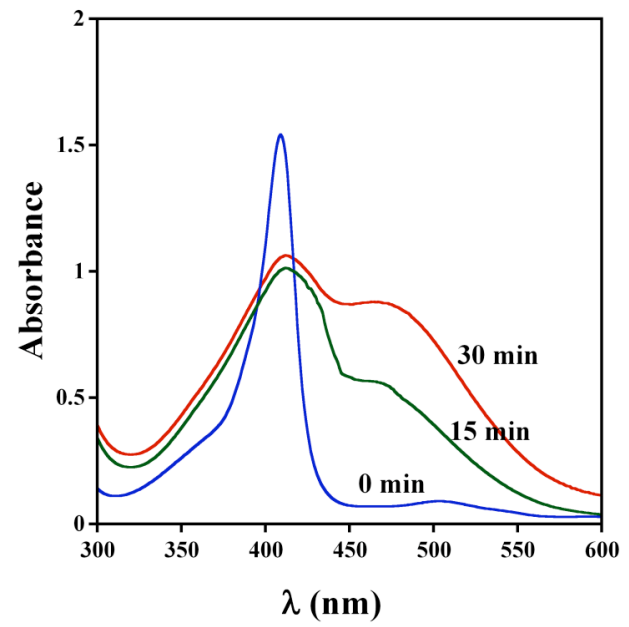

Figure S1. Assay of guiacol solution showing the formation of product absorbing at $470 \mathrm{~nm}$ upon exposure to $\mathrm{Mb}$ and $\mathrm{H}_{2} \mathrm{O}_{2}$. Conditions: $15 \mu \mathrm{M} \mathrm{Mb}, 1 \mathrm{mM} \mathrm{H}_{2} \mathrm{O}_{2}, 4$ $\mathrm{mM}$ guiacol, $10 \mathrm{mM}$ pH 5.5 acetate buffer. $\mathrm{Mb}$ peak is at $410 \mathrm{~nm}$ : reaction product from guiacol oxidation is at $470 \mathrm{~nm}$.

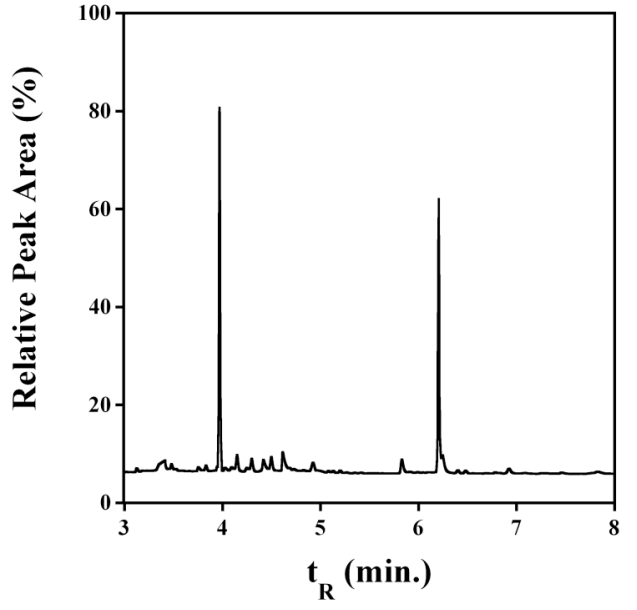

Figure S2. GC chromatogram of a standard solution of styrene (4 min.) and styrene oxide (6 min.), $2 \mathrm{mM}$ each.

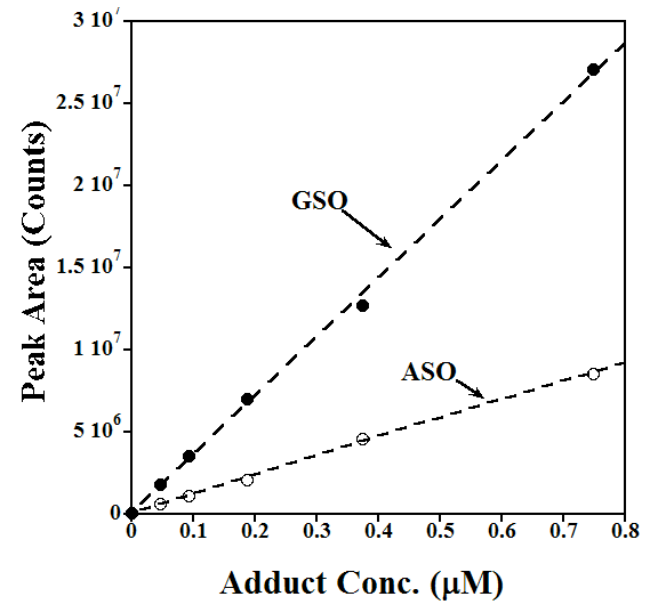

Figure S3. Calibration curve of LCMS peak area response for Gua-styrene oxide (GSO) and Ade-styrene oxide (ASO). 

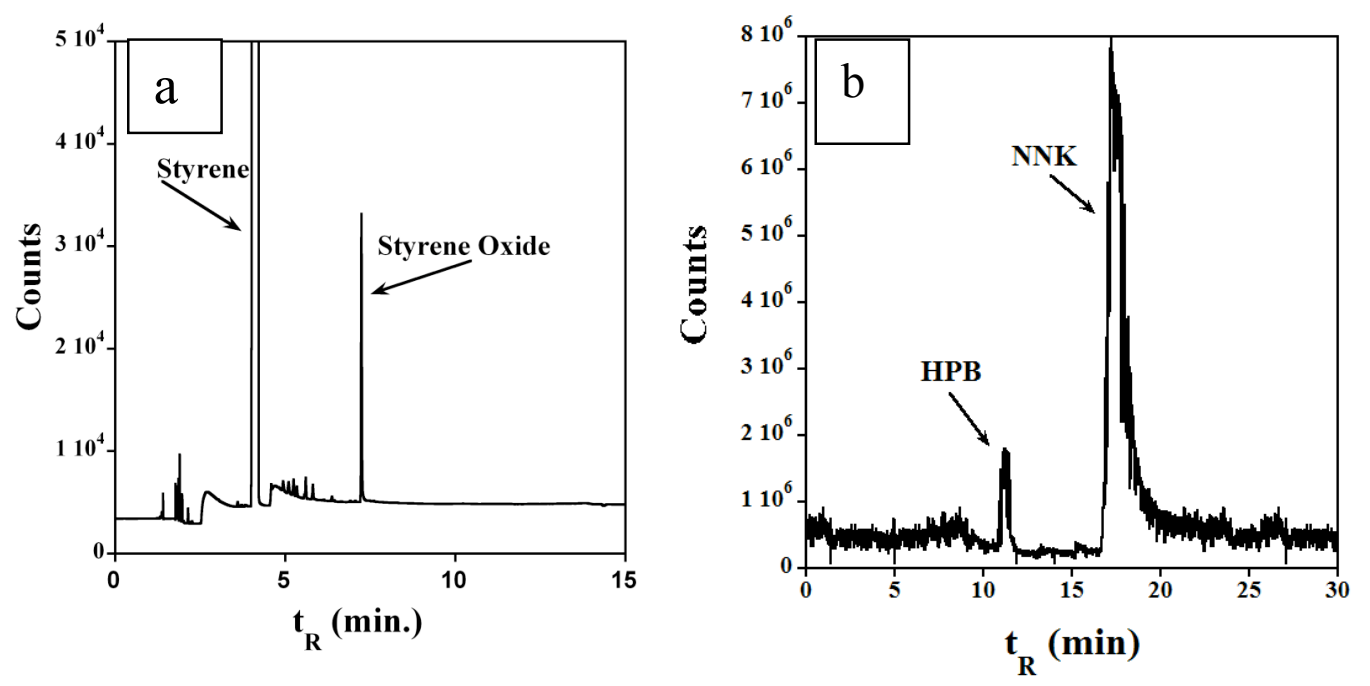

Figure S4. Chromatograms obtained after 10 min. reactions catalyzed by cyt P450 2E1 films on microbeads for conversion of (a) styrene to styrene oxide and (b) NNK to HPB. See experimental section of paper for conditions.

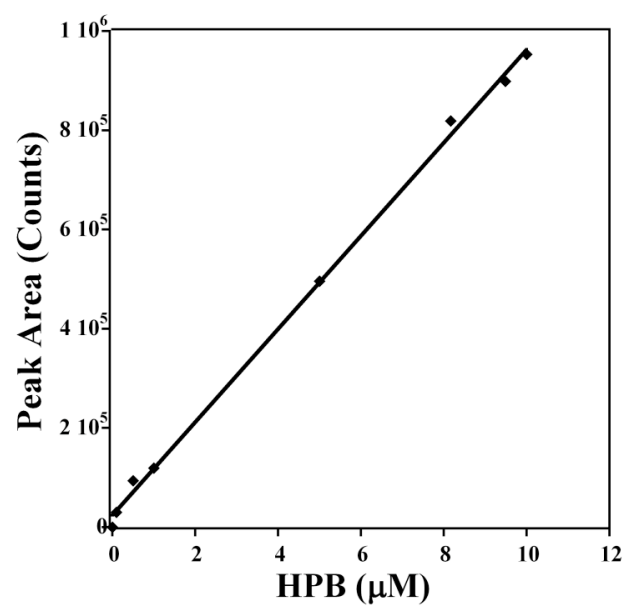

Figure S5. Calibration curve showing influence of increasing concentration of HPB on the LC peak area. See experimental section of paper for conditions.
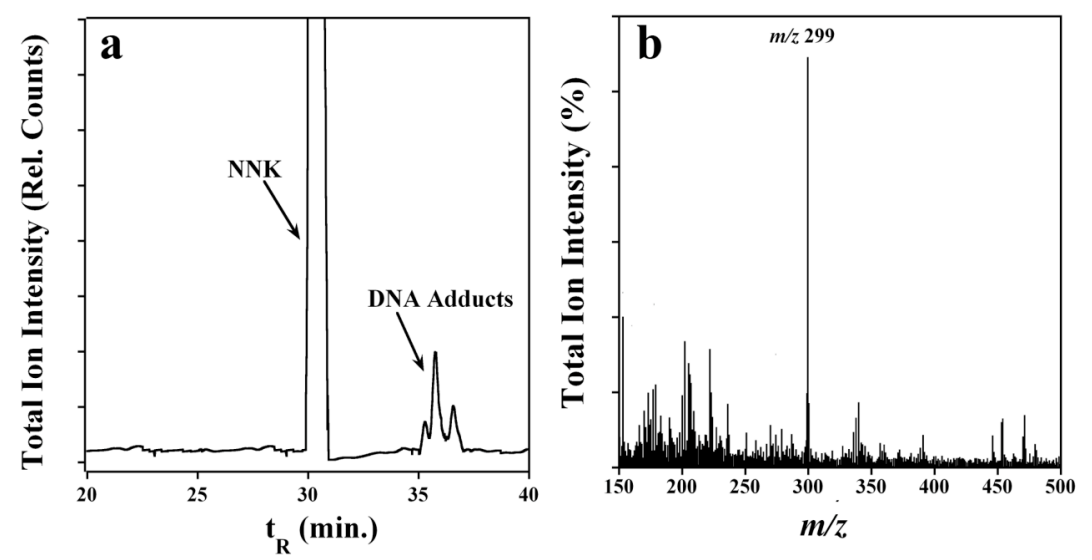

Figure S6. TIC CapLC/MS Chromatogram (a) and mass spectrum (b) of hydrolysate recovered after neutral thermal hydrolysis of DNA/CYP2E1 films following reaction with NNK. See experimental section of paper for conditions. 

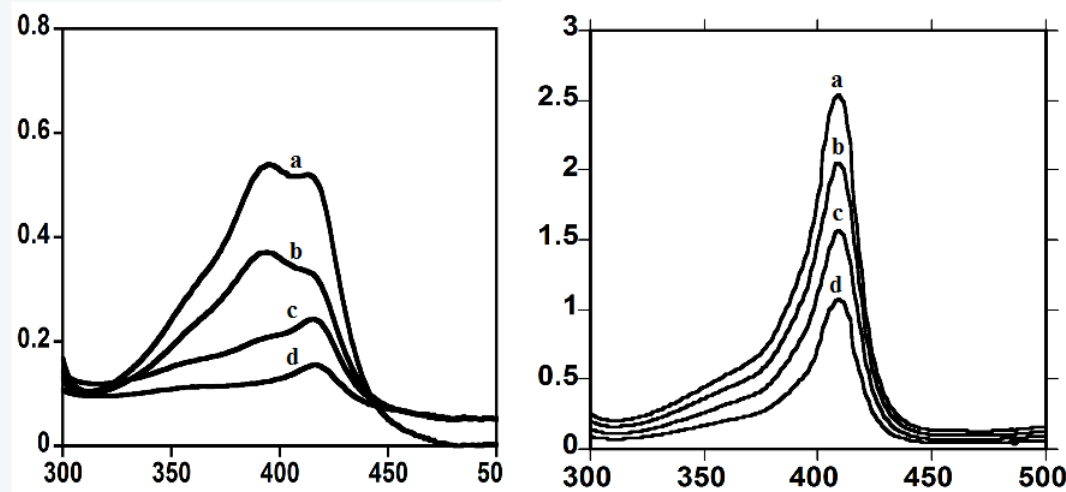

Figure S7. UV spectra showing absorbance spectra of cyt P450cam (on left) and $\mathrm{Mb}$ (on right) remaining in solution after $30 \mathrm{~min}$ absorption onto the silica-bead microsphere films for each respective layer. Graph on left: (a) spectrum of cyt P450cam in solution before absorption, (b) cyt P450cam left after 1 layer adsorption; (c) cyt P450

left after 2 layers adsorbed; (d) cyt P450 left after 3 layers adsorbed. Graph on right: (a) Mb solution before absorption; (b) Mb left after 1 layer adsorbed; (c) Mb left after 2 layers adsorbed; (c) Mb left after 3 layers adsorbed. 